\title{
Multiblock Thermoplastic Polyurethanes: In Situ Studies of Structural and Morphological Evolution under Strain
}

\author{
Denis V. Anokhin ${ }^{1,2, *}$, Marina A. Gorbunova ${ }^{1} \mathbb{D}$, Ainur F. Abukaev ${ }^{1,3} \mathbb{D}$ and Dimitri A. Ivanov ${ }^{1,2,4} \mathbb{D}$ \\ 1 Institute for Problems of Chemical Physics Russian Academy of Sciences, Semenov Prospect 1, \\ 142432 Chernogolovka, Russia; mflute2008@yandex.ru (M.A.G.); abukaev.af@phystech.edu (A.F.A.); \\ dimitri.ivanov.2014@gmail.com (D.A.I.) \\ 2 Faculty of Fundamental Physical and Chemical Engineering, Lomonosov Moscow State University, \\ 1 Leninskie Gory, 119991 Moscow, Russia \\ 3 Moscow Institute of Physics and Technology, Institutskiy per. 9, 141700 Dolgoprudny, Russia \\ 4 Institut de Sciences des Matériaux de Mulhouse-IS2M, CNRS UMR 7361, Jean Starcky, 15, \\ F-68057 Mulhouse, France \\ * Correspondence: deniano@yahoo.com; Tel.: +7-905-509-35-21
}

Citation: Anokhin, D.V.; Gorbunova M.A.; Abukaev, A.F.; Ivanov, D.A. Multiblock Thermoplastic Polyurethanes: In Situ Studies of Structural and Morphological Evolution under Strain. Materials 2021, 14, 3009. https://doi.org/ $10.3390 /$ ma14113009

Academic Editor: Dario Pasini

Received: 6 May 2021

Accepted: 29 May 2021

Published: 1 June 2021

Publisher's Note: MDPI stays neutral with regard to jurisdictional claims in published maps and institutional affiliations.

Copyright: (c) 2021 by the authors. Licensee MDPI, Basel, Switzerland. This article is an open access article distributed under the terms and conditions of the Creative Commons Attribution (CC BY) license (https:// creativecommons.org/licenses/by/ $4.0 /)$.

\begin{abstract}
The structural evolution of multiblock thermoplastic polyurethane ureas based on two polydiols, poly(1,4-butylene adipate (PBA) and poly- $\varepsilon$-caprolactone (PCL), as soft blocks and two diisocyanites, 2,4-toluylene diisocyanate (TDI) and 1,6-hexamethylene diisocyanate (HMDI), as hard blocks is monitored during in situ deformation by small- and wide-angle X-ray scattering. It was shown that the urethane environment determines the crystal structure of the soft block. Consequently, two populations of crystalline domains of polydiols are formed. Aromatic TDI forms rigid domains and imposes constrains on the crystallization of bounded polydiol. During stretching, the TDIpolydiol domains reveal limited elastic deformation without reorganization of the crystalline phase. The constrained lamellae of polydiol form an additional physical network that contributes to the elastic modulus and strength of the material. In contrast, polydiols connected to the linear semiflexible HMDI have a higher crystallization rate and exhibit a more regular lamellar morphology. During deformation, the HMDI-PBA domains show a typical thermoplastic behavior with plastic flow and necking because of the high degree of crystallinity of PBA at room temperature. Materials with HMDI-PCL bonding exhibit elastic deformation due to the low degree of crystallinity of the PCL block in the isotropic state. At higher strain, hardening of the material is observed due to the stress-induced crystallization of PCL.
\end{abstract}

Keywords: thermoplastic polyurethane ureas; shape memory materials; synchrotron SAXS/WAXS; polymer deformation; lamellar morphology; poly- $\varepsilon$-caprolactone; poly(1,4-butylene adipate)

\section{Introduction}

Recently, a new class of materials adaptive to external factors has started to rapidly develop. They can be exemplified by thermoplastic elastomers based on semi-crystalline polyurethanes (TPU) and polyurethane-ureas (TPUU). Such materials combining elasticity and strength have been already actively used in medicine for the engineering of tissues, plasters, sutures, implants, as well as in other areas [1-3]. TPU and TPUU are linear block copolymers consisting of thermodynamically incompatible soft (SB) and hard (HB) blocks that undergo a microphase separation. The soft segment is formed by polyester or polyether diols such as poly- $\varepsilon$-caprolactone (PCL) [4,5], poly(1,4-butylene adipate) (PBA), and their mixtures [6,7], poly-L-lactide [8], poly(ethylene glycol) [9], etc. The hard blocks are diol-urethane or urea fragments synthesized from aromatic diisocyanates (2,4-toluene diisocyanate), cycloaliphatic (isophoron diisocyanate), and aliphatic (1,6-hexamethylenediisocyanate) compounds and chain extenders (1,4-butanediol, diamine, and 2-aminoethanol). 
Apart from chemical composition, the mechanical, thermal, and relaxation properties of TPU and TPUU depend on the thermal history [10-12]. Thus, semi-crystalline polyurethanes are able to fix their temporary shape during deformation and further restore the original shape after heating above a switching temperature, i.e., they show the shape memory effect (SME) $[13,14]$. In a previous publication, it was shown that SME is determined by transition of the TPUU between three morphological states: (1) semi-crystalline lamellar morphology of isotropic film in a permanent shape, (2) fibrillar morphology with extended-chain crystals of the soft block after film stretching to a temporary shape, and (3) phase-separated state of the block copolymer in the amorphous state after shape recovery above the switching temperature [15]. At present, the attention of researchers is directed to studies of thermomechanical properties of adaptive TPUU [16-19]. However, the relationship between the chemical composition, nanoscale morphology, and thermomechanical characteristics is far from being fully understood.

Synchrotron small- and wide-angle X-ray scattering (SAXS/WAXS) is a powerful technique for analysis of polymer structure. The high brilliance of the X-ray source allows monitoring structural and morphological evolution with adequate time resolution. In particular, a combination of SAXS/WAXS with DSC [20-25], FTIR [26], and relaxometry [27] is capable of providing important information about structural evolution under external factors.

Structural investigations of TPUs are focused on a combination of two main processes: phase separation and ordering of HB [22,28]. The size and packing quality depend on the type of diisocyanate, its content, and preparation conditions. Particularly, the growth of $\mathrm{HB}$ content and annealing at elevated temperature stimulate an association process with an increase of HB domain size and relaxation of internal stress [21,22].

The most efficient approach combines SAXS/WAXS with uniaxial strain at different temperatures. Classical models of deformation of semi-crystalline polymers and block copolymers consider the continuous increase of a long period during stretching [29]. As a result of the specific chemical structure, polyurethanes possess fundamentally different structural evolution during deformation [30-33]. Particularly, TPU diffractograms often show a retardation of SAXS peak shift during film deformation, which indicates that the morphology is not related to the sequence of hard and soft domains [34,35]. A detailed study of TPU deformation was performed using in situ SAXS/WAXS experiments during deformation [36-38].

In studies of TPU based on polytetrahydrofurane (PTHF1000), methylene diphenyl diisocyanate (MDI), and 1,4-butanediol, Stribeck et al. explained a considerable retardation of the SAXS peak with respect to deformation by "paracrystalline" morphology of the HB. The authors suggested that a considerable fraction of the macroscopic strain must be realized in "poorly arranged entities" that do not contribute to the SAXS maximum because of absence of quasiperiodicity. In contrast, "well-arranged ensembles" are hardly deformed during strain and give a main contribution to the SAXS peak. At high deformation, tie polymer chains start to be pulled out from "well-arranged ensembles", resulting in a release of stress and shrinking of the long period (sacrifice-and-relief mechanism) [39,40].

It should be mentioned that despite numerous publications on structural evolution of TPUs under strain, only a few of them discuss the crystallization of soft block [41,42]. This can be explained by the low soft block content and small molecular weight of polydiols, which are used in most of the studies. Thus, the impact of soft block crystallinity, distribution of crystalline domains, and the size and kinetics of formation on macroscopic properties has been not well studied yet.

In the present work, the structural evolution of multiblock thermoplastic polyurethane urea based on two polydiols (poly(1,4-butylene adipate diol) and poly- $\varepsilon$-caprolactone diol) and two diisocyanites (diisocyanates (2,4-toluylene diisocyanate and 1,6-hexamethylene diisocyanate) is monitored as a function of temperature and strain during in-situ SAXS / WAXS experiments. 


\section{Materials and Methods}

\subsection{Materials}

Poly(1,4-butylene adipate) diol (PBA) (Huakai Resin Co., Ltd., Shandong, China, $\mathrm{Mn}=2000 \mathrm{Da}$ ) and poly- $\varepsilon$-caprolactone diol (PCL) (Merck KGaA, Darmstadt, Germany, $\mathrm{Mn}=2000 \mathrm{Da}$ ) were dried in vacuum for $4 \mathrm{~h}$ at $80{ }^{\circ} \mathrm{C}$. The $\mathrm{OH}$ groups content determined by chemical method [43] was $1.7 \mathrm{w} / \mathrm{w} \%$. Diisocyanates (2,4-toluylene diisocyanate (TDI) and 1,6-hexamethylene diisocyanate (HMDI)) (Merck KGaA, Darmstadt, Germany) were distilled in vacuum at 50-55 ${ }^{\circ} \mathrm{C} / 12 \mathrm{~mm} \mathrm{Hg}$ and stored in sealed ampoules. Chain elongation agents (2-amino-1-ethanol (EA) and 1,4-butanediol (BD)) were distilled over freshly powdered calcium hydride under a reduced pressure. Dibutyltin dilaurate (DBTDL) catalyst purchased from Aldrich was used as received. The disappearance of $\mathrm{OH}$ and $\mathrm{NCO}$ groups and the appearance of urethane groups were monitored by IR spectroscopy.

\subsection{Synthesis of Multiblock Thermoplastic Polyurethane Urea}

The synthesis of multiblock copolymers was carried out by the three-reactor method developed earlier by us [15]. At the first stage (reactor 1) of TPUU synthesis, a macrodiol from polydiol (PBA or PCL) and TDI in the presence of two chain extenders (BD and EA) was prepared. In the second stage (reactor 2), a macrodiol from polydiol (PBA or PCL), HMDI, and chain extender (BD) were synthesized. Then, the reaction products from the two reactors were mixed and linked by HMDI added in a stoichiometric ratio $[\mathrm{NCO}] /[\mathrm{OH}]=1$. In the result, four polymers have been synthesized, where PCL and PBA are linked in different combinations with bulky aromatic TDI and more flexible and elongated HMDI (Table 1). Upon reaching the degree of conversion of NCO groups $\approx 98 \%$, the reaction mass was poured into a flat Teflon container and dried at $40{ }^{\circ} \mathrm{C}$ during the day until constant weight. The control of the full course of the reaction was carried out by infrared spectra on the complete disappearance of absorption bands of isocyanate $\left(\nu \mathrm{NCO}=2271 \mathrm{~cm}^{-1}\right)$ and hydroxyl groups $\left(\nu \mathrm{OH}=3620 \mathrm{~cm}^{-1}\right)$. Molecular characteristics of the TPUUs were determined by gel permeation chromatography (GPC) in tetrahydrofuran using a Waters GPCV 2000 chromatograph equipped with refractometric and viscosimetric detectors. The number and weight average molecular weight of all four polymers were the following: $\mathrm{Mn}=40,000 \mathrm{Da}, \mathrm{Mw}=80,000 \mathrm{Da}, \mathrm{Mw} / \mathrm{Mn}=2$. The scheme of synthesis of TPUM is presented in Scheme 1.

The molar ratio of the reaction was determined from which HS content was estimated. The hard segment (HS) was defined as:

$$
\mathrm{HS}=\frac{\mathrm{m}(\mathrm{TDI}+\mathrm{HMDI})+\mathrm{m}(\mathrm{AE}+\mathrm{BD})}{\mathrm{m}(\mathrm{TDI}+\mathrm{HMDI})+\mathrm{m}(\mathrm{AE}+\mathrm{BD})+\mathrm{mPolyols}} .
$$

Table 1 shows the composition and ratio of components in the synthesized TPUUs.

Table 1. Chemical composition of studied TPUUs.

\begin{tabular}{ccccccc}
\hline \multirow{2}{*}{ Polymer } & \multicolumn{2}{c}{ Polymer Composition } & \multicolumn{4}{c}{ Mass Fraction of Reagents, $\%$} \\
\cline { 2 - 7 } & P1 & P2 & Polyol & Diisocyanate Chain Extender & SS/HS \\
\hline TPUU-AA & PBA & PBA & 69 & 23 & 8 & 2.2 \\
TPUU-BB & PCL & PCL & 69 & 23 & 8 & 2.2 \\
TPUU-AB & PBA & PCL & 69 & 23 & 8 & 2.2 \\
TPUU-BA & PCL & PBA & 68 & 23 & 8 & 2.2 \\
\hline
\end{tabular}




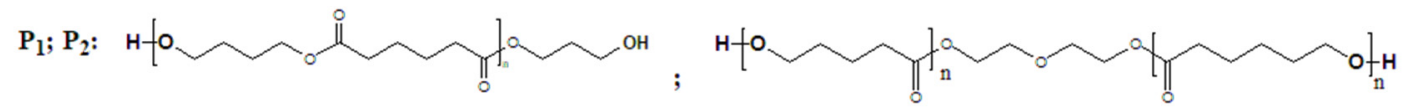

I stage

$$
\text { III stage stage }
$$

Scheme 1. General scheme of synthesis of macrodiol A (I stage), macroisocyanate B (II stage) and studied TPUUs (III stage).

\subsection{Experimental Techniques}

The structural investigation was performed at the BM26 beamline of the European Synchrotron Radiation Facility (ESRF) in Grenoble, France. The beamline is equipped with Pilatus $1 \mathrm{M}$ (SAXS, s-range 0.002-0.04 $\AA^{-1}$ ) and Pilatus 300k (WAXS, s-range 0.08-0.5 $\AA^{-1}$ ) detectors. The experiments used X-ray photons with a wavelength of $1.04 \AA$, and the spot size of the beam on the sample was $0.65 \times 0.65 \mathrm{~mm}$. The central part of the dogbone-like test bars for analysis had dimensions of $22 \times 6 \times 0.7 \mathrm{~mm}$. The in situ strain experiments were carried out in a Linkam TST350 tensile stage with a maximum force of $20 \mathrm{~N}$ and strain rate of $1 \mathrm{~mm} / \mathrm{min}$. The strain rate was decreased compared to tensile tests to minimize the variation of deformation during SAXS/WAXS exposure (12 s). Shape recovery was measured during heating of stretched film at a heating rate $5^{\circ} \mathrm{C} / \mathrm{min}$ to a temperature above the melting point of the soft block e.g., $80{ }^{\circ} \mathrm{C}$, and rapid cooling to room temperature. The two-dimensional diffraction patterns were analyzed using a program package developed in Igor Pro Program package (Wavemetrics Ltd., Portland, OR, USA) [44-46].

The ex situ tensile tests were performed on a Zwick TC-FR010TH Material Testing Machine at $50 \mathrm{~mm} / \mathrm{min}$ stretching rate using the same samples as for SAXS/SAXS strain experiments. This test was performed according to the ASTM-D638 Type IV.

\section{Results and Discussions}

The stress-strain curves of TPUU depending on the composition of the soft block are shown in Figure 1. It can be seen that TPUU-BB with PCL as a soft block demonstrates the stress-strain curve of a typical elastomer with low Young's modulus (E) and the highest elongation at break $\left(\varepsilon_{\mathrm{r}}\right)$ (cf. black curve in Figure 1). The elasticity in TPUU-BB is provided by the connection of PCL with a more flexible linear urethane fragment. The mechanical characteristics of TPUUs are summarized in Table 1. TPUU-AA and TPUU-BA containing the PBA block linked with HMDI demonstrate the mechanical behavior typical of stiff 
thermoplastics: high Young's modulus and plastic flow with the formation of a neck in the strain range of $50-400 \%$ (green and blue curves in Figure 1). The stiffness of the materials stems from a limited mobility of PBA chains bounded with bulky rigid TDI-based urethane (Figure 1). This clearly indicates that the type of polydiol is important in the design of SME polymers. The mechanical characteristics are summarized in Table 2.

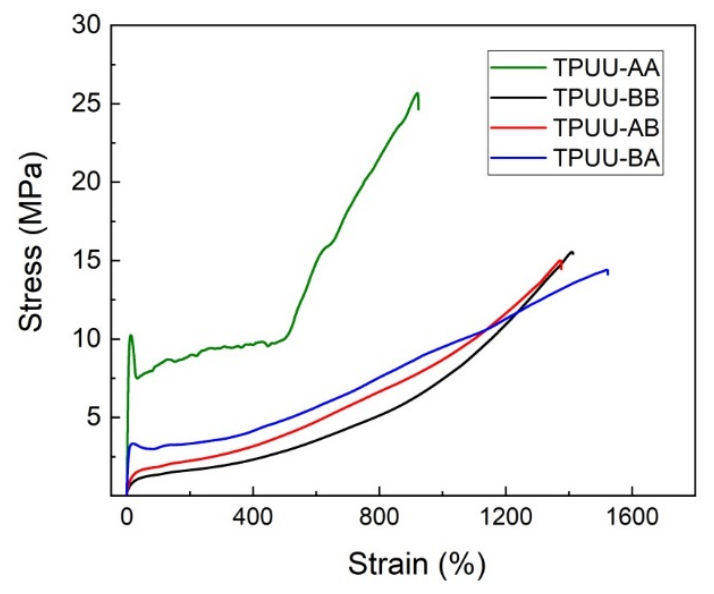

Figure 1. Stress-strain curves of the studied TPUUs.

Table 2. Mechanical characteristics of TPUUs.

\begin{tabular}{cccc}
\hline Polymer & $\varepsilon_{\mathbf{r}}, \%$ & $\sigma_{\mathbf{r}}, \mathbf{M P a}$ & E, $\mathbf{M P a}$ \\
\hline TPUU-AA & $807 \pm 78$ & $22 \pm 3$ & $199 \pm 4$ \\
TPUU-BB & $1445 \pm 27$ & $15 \pm 1$ & $7 \pm 1$ \\
TPUU-AB & $1445 \pm 52$ & $16 \pm 1$ & $11 \pm 1$ \\
TPUU-BA & $1340 \pm 84$ & $13 \pm 2$ & $59 \pm 2$ \\
\hline
\end{tabular}

The variation of mechanical properties is related to the specific morphology of the films with different bonding of urethane of polydiol. In this paper, the reorganization of the morphology was studied in situ by SAXS/WAXS analysis using a brilliant synchrotron source.

Figure 2 shows changes in the film organization during stretching. Isotropic sample TPUU-AA reveals a ring characteristic of PBA crystalline lamellar ordering with a long period of $\mathrm{L}_{S B}=14.7 \mathrm{~nm}$ (Figure 2A). In addition, on the 1D-reduced curve, a broad peak with a maximum at $9.7 \mathrm{~nm}$ can be identified (Figure 3A, black curve). This peak cannot be attributed to the second order of the long period, and its origin can be understood using the in situ film deformation experiment. Under small reversible strains, the isotropic ring transforms into a four-spot pattern, indicating reorientation of the PBA lamellae along the drawing direction [47]. An increase of half-width of the crystalline peaks in the WAXS region indicates the fragmentation of large PBA lamellae under stress (Figure 4A, blue curve). The d-spacing of the second peak increases to $10.4 \mathrm{~nm}$, and it organizes in broad "clouds" positioned along the direction of stretching (Figure 3A, blue curve). At further strains, the four-spot lamellar peak disappears due to the lack of phase contrast during plastic flowing of the material in the neck. Meantime, the equatorial orientation of the second peak becomes more pronounced, and its position gradually increases to $12.9 \mathrm{~nm}$ for $\varepsilon=300 \%$ (Figure 3A, dark blue curve). After release of stress, the film of TPUU-AA shows high residual deformation $-200 \%$ in the neck. The intensity of the second peak increases because of enhanced phase contrast and the spacing decreases to $\mathrm{L}_{\mathrm{HB}}=11.6 \mathrm{~nm}$ (Figure 3A, green curve). Interestingly, this peak is preserved even after heating to above the melting point of the PBA crystal phase (Figures $3 \mathrm{~A}$ and $4 \mathrm{~A}$, yellow curves). Consequently, the peak can be assigned to the phase-separated morphology of soft and hard segments rather than to the stacking of PBA crystals [15]. We expect that this spacing reflects the distance 
between the rigid TDI domains that surround the PBA block (see Figure 5A, left). The PBA chains bonded to TDI crystallize under hard geometric constraints $[48,49]$. The presence of stressed tie chains in such domains prevents the constrained PBA lamellae from unfolding during stretching with small elastic deformation of the amorphous phase (Figure 5A, right). In contrast, the PBA lamellae surrounded by relatively flexible linear urethane fragments are formed in soft confinement. During application of strain, these regions behave as typical semi-crystalline flexible-chain polymers with plastic flow and the formation of fibrillar crystals. The difference in crystallization conditions of PBA connected to aromatic and linear urethanes can illustrate the appearance of SAXS maximum at $20.4 \mathrm{~nm}$ during the deformation of amorphous TPUU-AA after heating to $80{ }^{\circ} \mathrm{C}$ (Table 3), indicating crystallization of the HMDI-surrounded soft blocks before the TDI-surrounded ones. Two populations of the PBA crystals generate two melting peaks in the DSC curve of the fresh TPUU-AA sample [14].

A
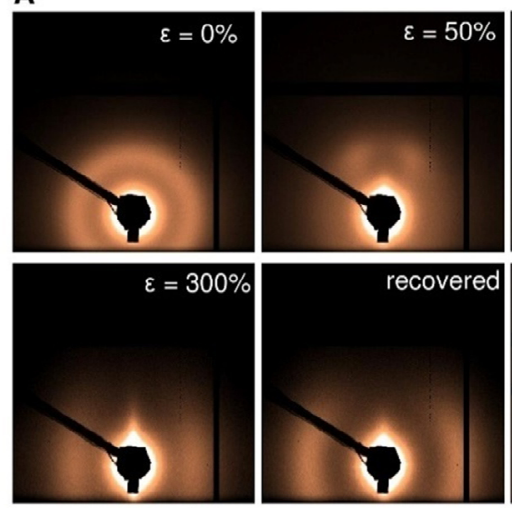

C
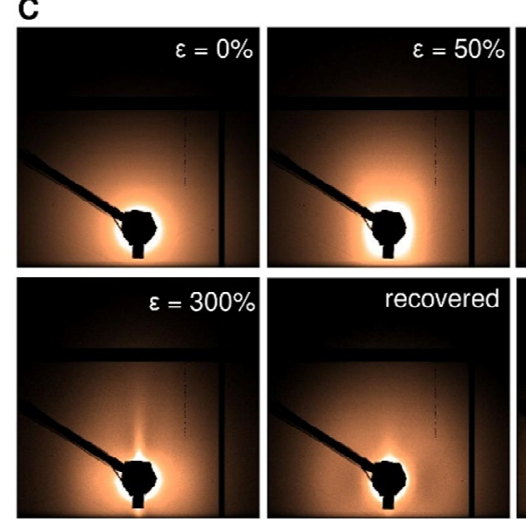
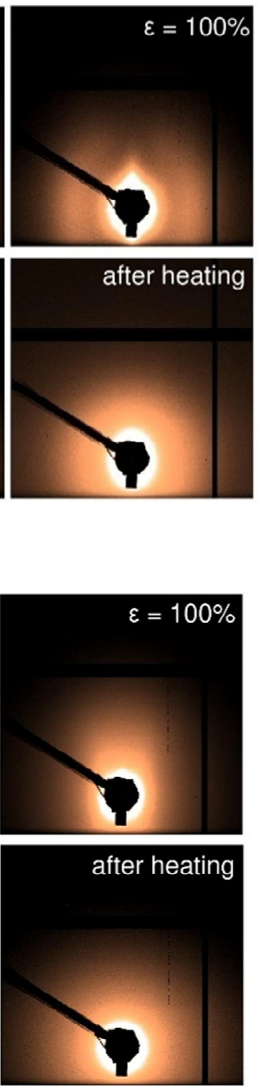

B
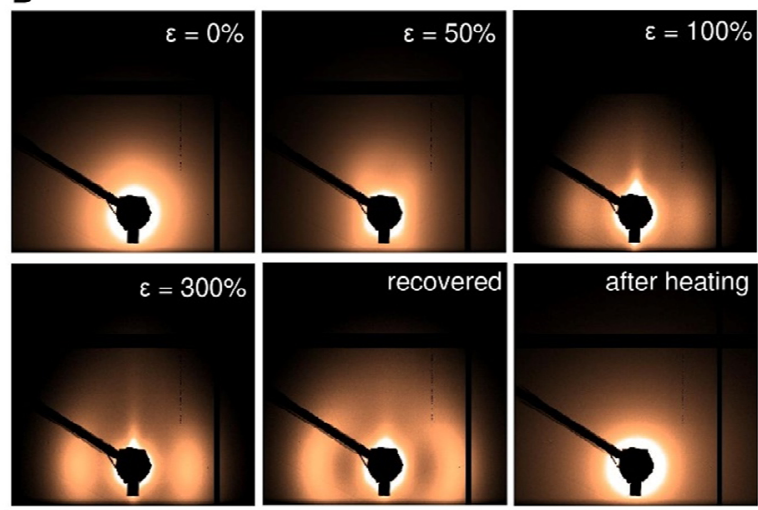

D
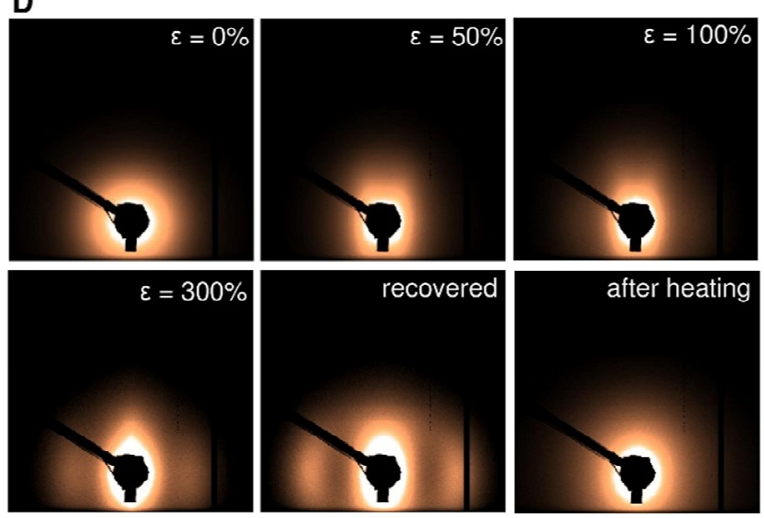

Figure 2. Two-dimensional (2D) SAXS patterns of the studied films: (A) TPUU-AA; (B) TPUU-BB; (C) TPUU-AB; (D) TPUU$\mathrm{BA}$, measured during strain, recovered after release of stress, and after heating to $60{ }^{\circ} \mathrm{C}$. Drawing direction is horizontal.

The replacement of well-crystallizable PBA soft block by PCL with a moderate crystallization rate at room temperature changes the morphology and corresponding mechanical characteristics of TPUU (Figure 2B). In the isotropic film, the lamellar SB peak is broader and shifted to smaller angles (Figures $2 \mathrm{~B}$ and $3 \mathrm{~B}$, red curve). During deformations up to $50 \%$, one can see an increase of both SB and HB periodicities (Figure 3B, black curve, Table 3). The intensity of the SB peak is concentrated in the direction normal to drawing (Figure 2B). On further stretching, the SB maximum from folded lamellae disappears without plastic flow of PCL chains (Figures $2 \mathrm{~B}$ and 3B, blue curve). At even higher deformations, WAXS reveals growing crystalline peaks corresponding to the stress-induced formation of fibrillar PCL crystals (Figure 4B, blue curve). For $\varepsilon=300 \%$, one observes a 
certain decrease of phase-separated $\mathrm{L}_{\mathrm{HB}}$ distance probably caused by "sacrifice-and-relief" mechanism described by Stribeck for MDI-based polyurethanes [39].

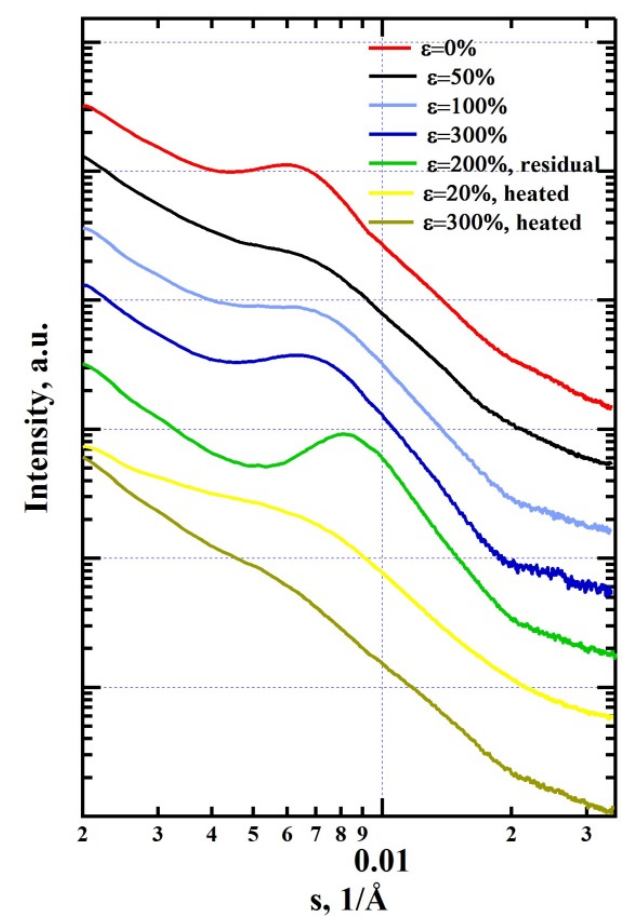

(A)

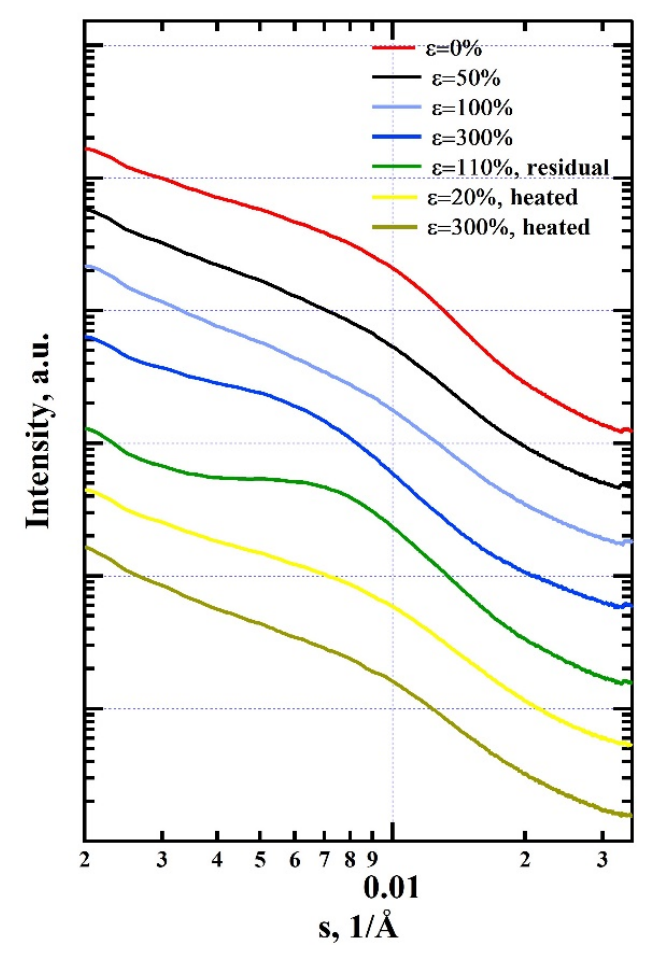

(C)

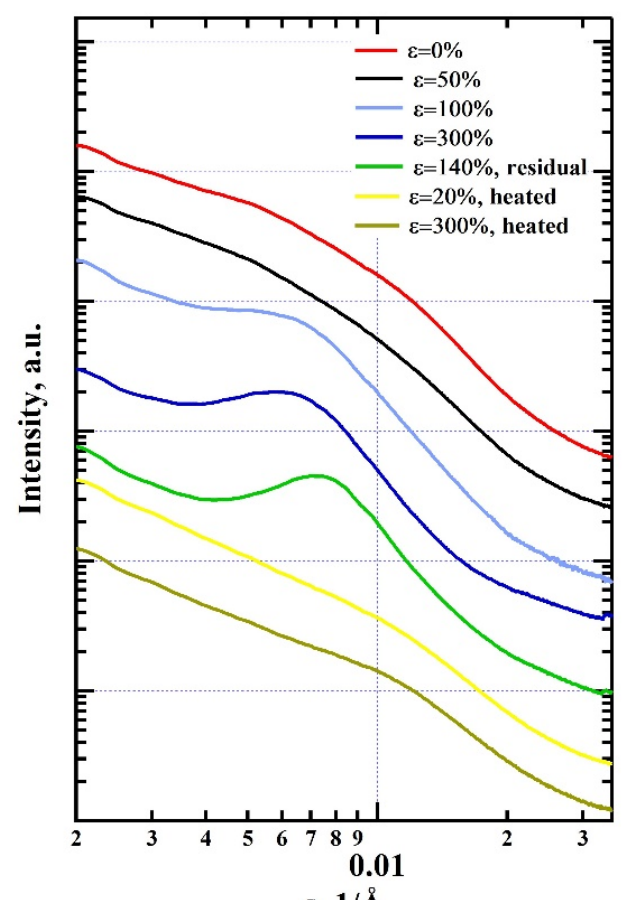

s, $1 / \AA$

(B)

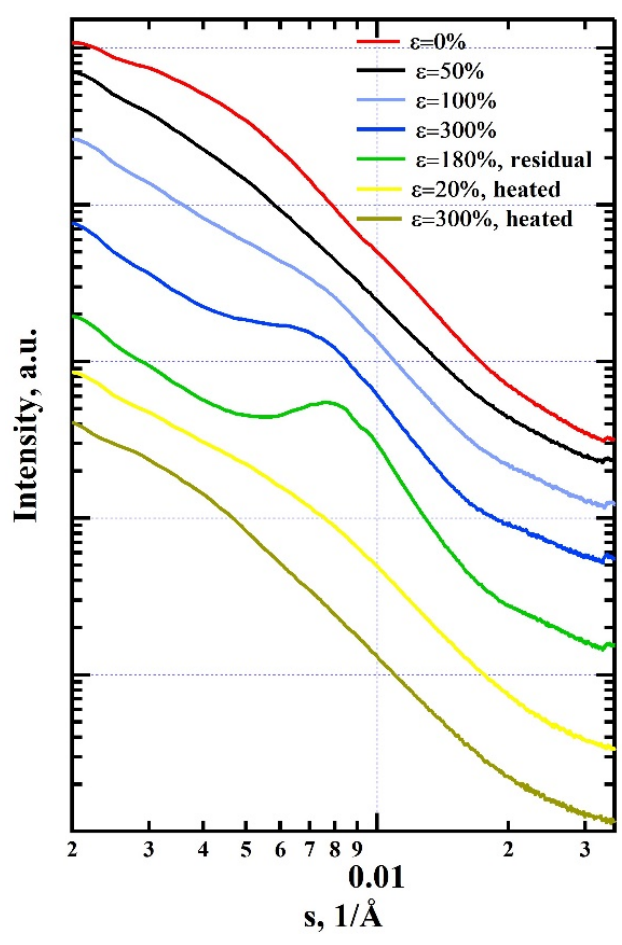

(D)

Figure 3. One-dimensional (1D)-reduced SAXS curves of the studied films: (A) TPUU-AA; (B) TPUU-BB; (C) TPUU-AB; (D) TPUU-BA, measured during deformation, recovered after release of stress, and after heating to $60{ }^{\circ} \mathrm{C}$. 
The same effect of decrease of $\mathrm{L}_{\mathrm{HB}}$ was detected during stretching of the amorphous film preliminarily heated above the melting point of PCL (Table 3). The peak due to phase separation is less pronounced probably because of the better miscibility of PCL with linear urethanes (Figure 3B, yellow curve). Interestingly, stretching of the initially amorphous film does not show any stress-induced crystallization (Figure 3B, brown curve). Generally, TPUU-BB with a PCL soft block possesses less regular lamellar organization. Rubber-like stress-strain curves and a higher increase of $\mathrm{L}_{\mathrm{SB}}$ and $\mathrm{L}_{\mathrm{HB}}$ indicate that both TDI-bounded and HMDI-bounded PCL chains do not form regularly folded lamellae.

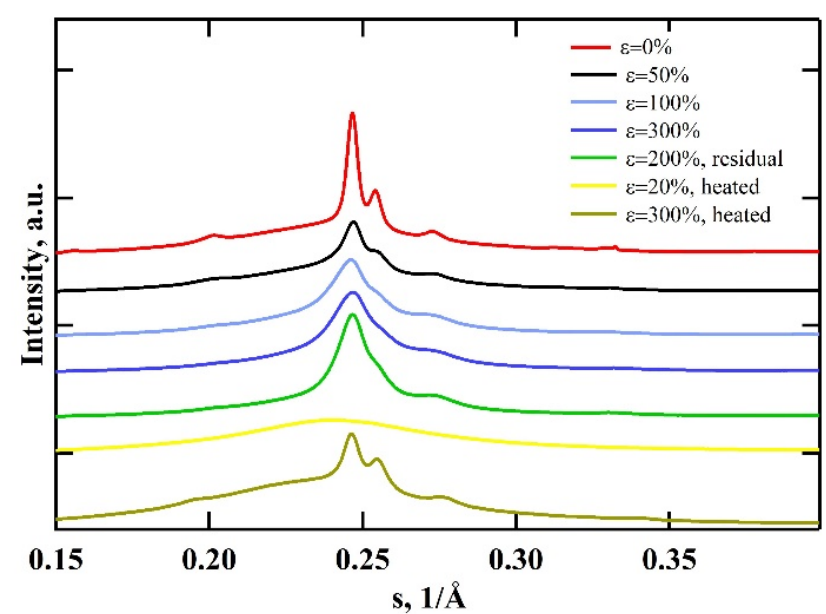

(A)

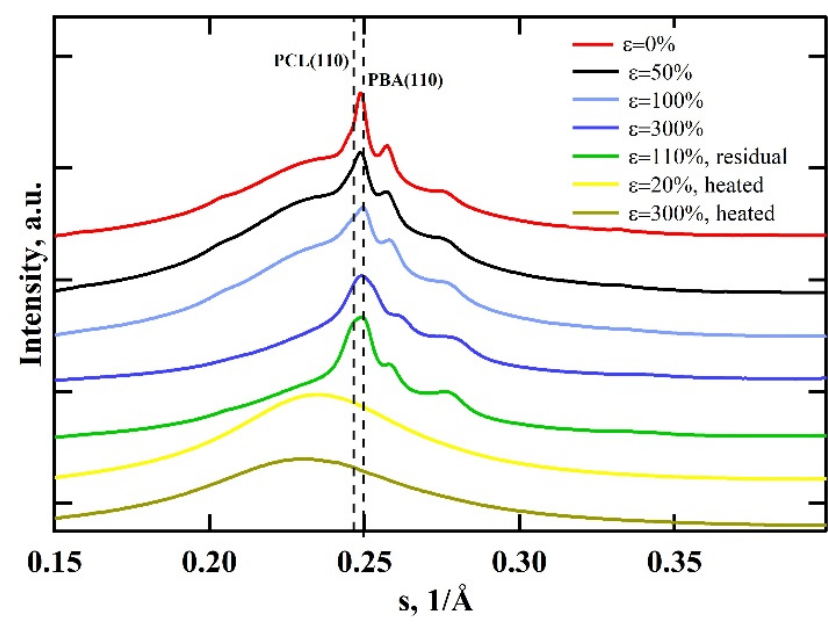

(C)

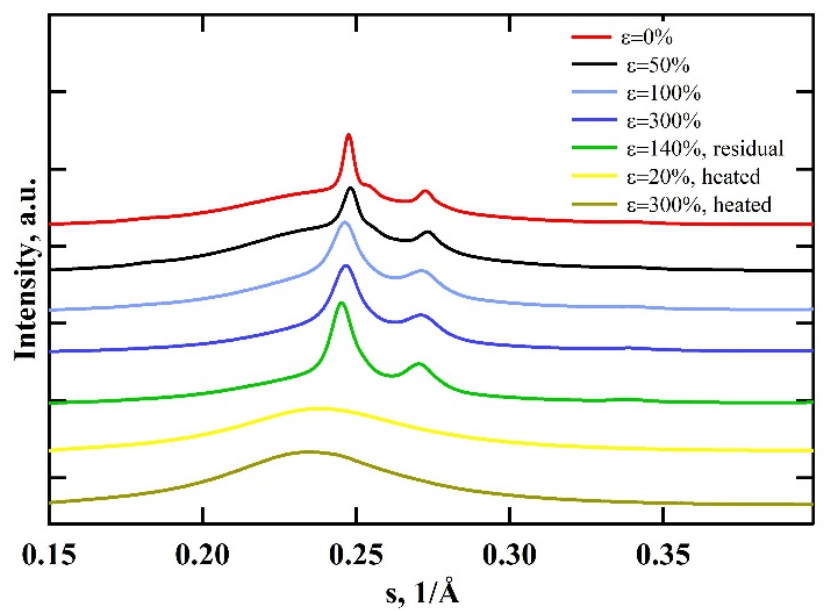

(B)

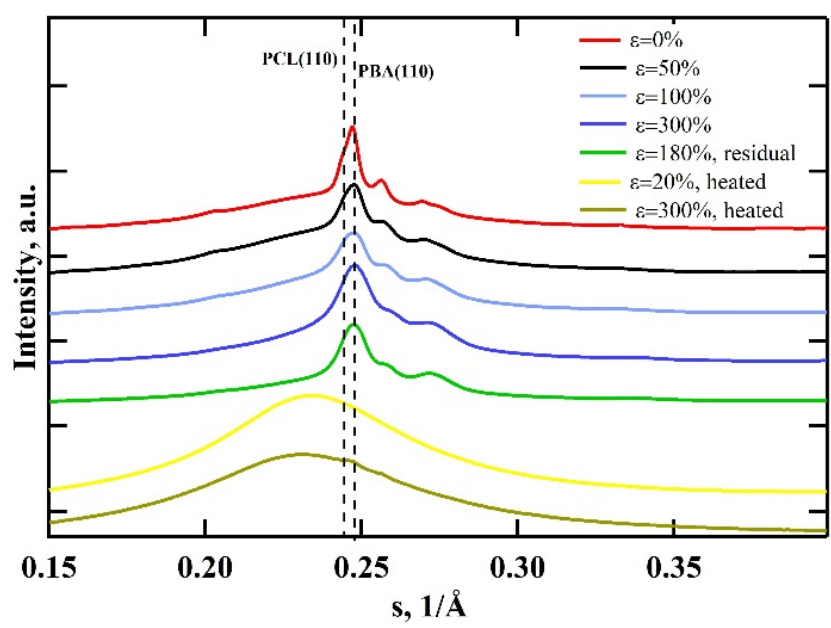

(D)

Figure 4. One-dimensional (1D)-reduced WAXS curves of the studied films: (A) TPUU-AA; (B) TPUU-BB; (C) TPUU-AB; (D) TPUU-BA, measured during deformation, recovered after release of stress, and after heating to $60{ }^{\circ} \mathrm{C}$. Vertical dashed lines point on positions of the (110) peaks of PBA and PCL. 

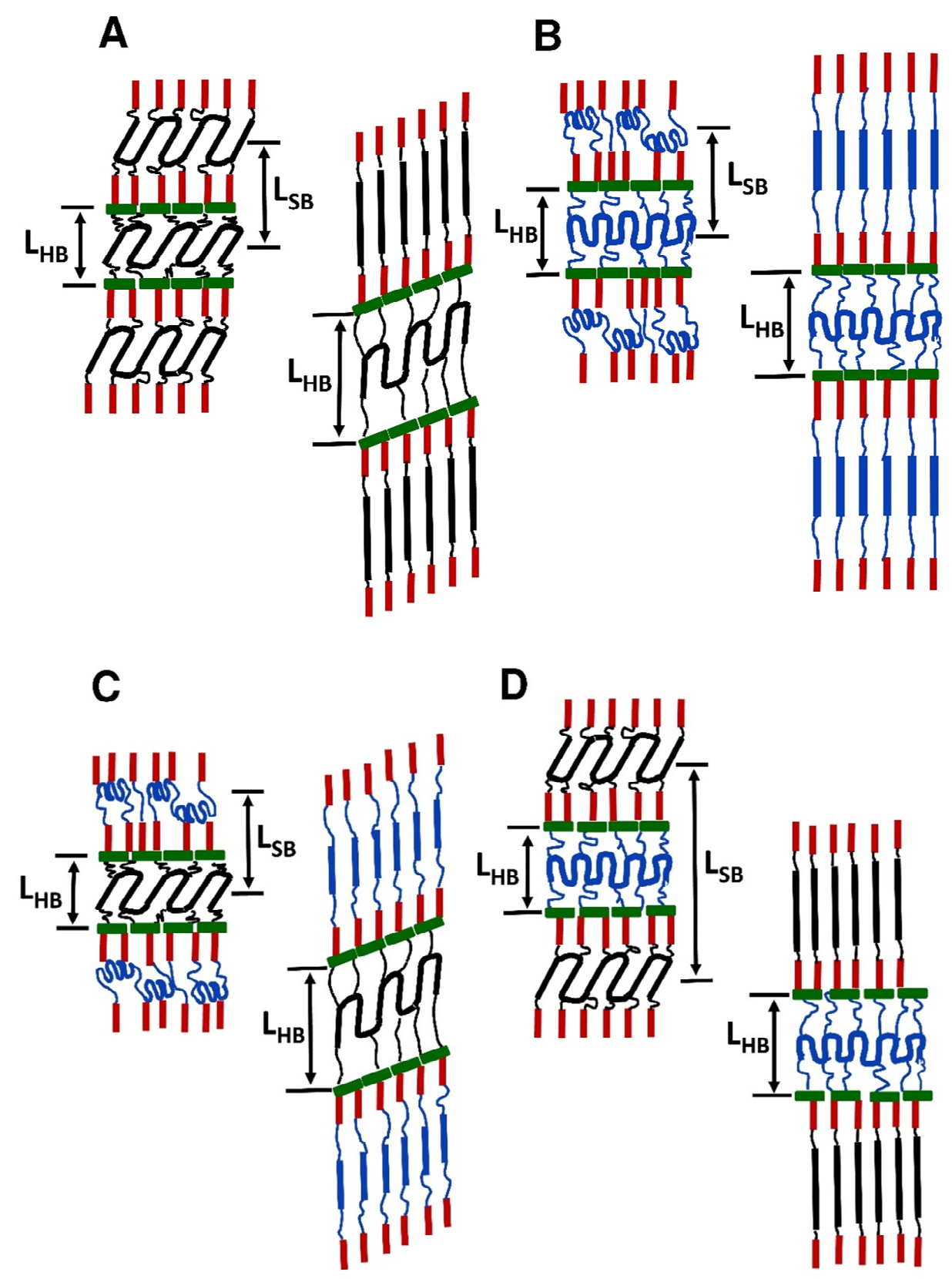

Figure 5. Schematics of morphology of the TDI (green), HMDI (red), PBA (black), and PCL (blue) regions in isotropic (left) and stretched to $\varepsilon=300 \%$ (right) films: (A) TPUU-AA; (B) TPUU-BB; (C) TPUU-AB; (D) TPUU-BA. Stretching direction is vertical.

In the case of TPUUs with both PBA and PCL soft blocks, an important role is played by the position of a particular polydiol in the multiblock chain. Isotropic sample TPUU-AB reveals the presence of a mainly crystalline phase of TDI-bounded PBA (Figure 4C, red curve). We suppose that PCL blocks surrounded by semi-flexible linear urethanes still have a low crystallization rate, resulting in the absence of correlation between PCL and PBA lamellae (Table 3). During deformation, the crystal fraction of PCL increases due to stress-induced crystallization and the weak SAXS maximum at $\mathrm{L}_{S B}=18.4 \mathrm{~nm}$ is visible up to $\varepsilon=100 \%$ (Figures $3 \mathrm{C}$ and $4 \mathrm{C}$ blue curves). PBA crystals surrounded by hard domains of TDI show a relatively small increase of $\mathrm{L}_{\mathrm{HB}}$ on deformation and absence of the peak orientation in the drawing direction (Figures $2 \mathrm{C}$ and $3 \mathrm{C}$ ). After the release of stress, the orientation of the phase-separated morphology almost completely disappears due to the 
high flexibility of the PCL blocks (Figure 3C, green curve). This sample demonstrates mechanical behavior that is intermediate between rubber-like and thermoplastic without necking but with orientational hardening (Figure 1, red curve and Figure 5C).

Table 3. Structural parameters of samples at different strain.

\begin{tabular}{|c|c|c|c|}
\hline Polymer & $\varepsilon, \%$ & $\mathrm{~L}_{\mathrm{HB}}, \mathbf{n m}$ & $\mathrm{L}_{\mathrm{SB}}, \mathrm{nm}$ \\
\hline \multirow{7}{*}{ TPUU-AA } & 0 & 9.7 & 14.6 \\
\hline & 50 & 10.8 & 14.0 \\
\hline & 100 & 12.8 & - \\
\hline & 300 & 12.9 & - \\
\hline & 200, restored & 11.6 & - \\
\hline & 20 , after heating & 9.7 & - \\
\hline & 300 , after heating & 9.4 & 20.4 \\
\hline \multirow{7}{*}{ TPUU-BB } & 0 & 9.6 & 15.6 \\
\hline & 50 & 10.3 & 17.8 \\
\hline & 100 & 14.7 & - \\
\hline & 300 & 14.3 & - \\
\hline & 140, restored & 12.5 & - \\
\hline & 20 , after heating & 9.1 & - \\
\hline & 300 , after heating & 8.6 & - \\
\hline \multirow{7}{*}{ TPUU-AB } & 0 & 10.8 & - \\
\hline & 50 & 11.2 & 16.3 \\
\hline & 100 & 12.4 & 18.4 \\
\hline & 300 & 14.8 & - \\
\hline & 110, restored & 12.3 & - \\
\hline & 20, after heating & 10.1 & - \\
\hline & 300 , after heating & 9.9 & - \\
\hline \multirow{7}{*}{ PTUU-BA } & 0 & 10.0 & 20.6 \\
\hline & 50 & 11.7 & 24.8 \\
\hline & 100 & 13.6 & - \\
\hline & 300 & 13.0 & - \\
\hline & 180 , restored & 11.4 & - \\
\hline & 20, after heating & 11.1 & - \\
\hline & 300 , after heating & 13.8 & 24.6 \\
\hline
\end{tabular}

In contrast, WAXS patterns of TPUU-BA with HMDI-bounded PBA chains reveal a high degree of crystallinity in the isotropic state with an approximately equal content of PBA and PCL crystals (Figure 4D, red curve). Thus, PCL chains constrained by a neighbor TDI hard domain show a better tendency to crystallize at room temperature than in the more mobile HMDI domains (Figure 5D). However, regular lamellae of HMDI-surrounded PBA blocks give high phase contrast, resulting in the enhanced SAXS maximum with increased distance $\mathrm{L}_{S B}=20.6 \mathrm{~nm}$ (Figure 3D, red curve). This peak transforms to a fourspot pattern at $\varepsilon=50 \%$ but further disappears due to the lack of phase contrast between $\mathrm{HB}$ and extended-chain PBA crystals (Figures 2D and 3D, blue curve). Interestingly, PCL chains in the TDI domain do not reveal significant deformation and stress-induced crystallization (Figure 4D, dark blue curve). In contrast to TPUU-AA, the HB peak of TPUU-BA shows very good azimuthal orientation in the drawing direction at high strain (Figure 2A,D). This can be attributed to bigger chain tilt in constrained PBA lamellae compared to the lamellae of PCL (Figure 5A,D). After heating above the melting point of PBA and PCL crystals, HMDI-surrounded PBA chains rapidly crystallize with the reappearance of maximum at $24.6 \mathrm{~nm}$ during the stretching of amorphous film (Figure 3D, yellow curve). This confirms that the crystallization of HMDI-surrounded PBA chains occurs faster than that of TDIsurrounded PBA with the formation of more regularly stacked lamellae. The presence of HMDI-surrounded PBA in TPUU provides relatively high residual deformation after the release of stress and a slow relaxation of strain that is important for the design of shape memory materials. 


\section{Conclusions}

In conclusion, the variation of chemical nature of polydiol and adjusted diisocyanates allows tuning the mechanical properties of resulting TPUUs from soft elastomers to rigid thermoplastics. Synchrotron SAXS/WAXS studies of a series of TPUUs reveal a complex change in morphology during deformation related to the superposition of phase separation of soft and hard blocks and crystallization of the polydiols. It was shown that TDI-bounded polydiols are constrained in rigid domains which, on the one hand, decrease the crystallization rate and regularity of lamellae but, on the other hand, preserve crystals from plastic flow during strain. In this case, constrained crystals of soft block play the role of an additional physical network imparting higher stiffness to the material. In the meantime, HMDI-bounded polydiols reveal higher crystallinity and faster crystallization from the melt. During deformation, these crystalline domains behave as typical semi-crystalline flexible-chain polymers. The TPUUs with HMDI-bounded PBA show plastic flow with the formation of extended-chain crystals, while HMDI-bounded PCL fragments reveal stress-induced crystallization. Thus, HMDI-rich domains are responsible for the elastic characteristics of the material: elongation at break, residual deformation, etc. Consequently, rigid aromatic TDI or semi-rigid linear HMDI form a different interface for two populations of crystallites of polydiols. A significant difference in crystallization kinetics at room temperature between PBA and PCL provides an additional tool for fine-tuning the thermoplastic properties and shape memory behavior.

In situ investigation of the structure and morphology of TPUU at different external stimuli allows finding the relationship between the structure and deformational properties that helps optimizing the composition of the soft block for desired mechanical characteristics.

Author Contributions: Conceptualization, D.V.A.; Data curation, A.F.A.; Formal analysis, D.V.A.; Investigation, M.A.G.; Methodology, M.A.G.; Supervision, D.V.A.; writing-original draft preparation, D.V.A.; Writing-review and editing, D.A.I. All authors have read and agreed to the published version of the manuscript.

Funding: This research was funded by Russian Foundation for Basic Research (Project No. 19-5315016) and carried out within the framework of the State Assignment (Topic No. 0089-2019-0012, State Registration No. AAA-A19-119032690060-9).

Institutional Review Board Statement: Not applicable.

Informed Consent Statement: Not applicable.

Data Availability Statement: The data presented in this study are available in article.

Conflicts of Interest: The authors declare no conflict of interest. The funders had no role in the design of the study; in the collection, analyses, or interpretation of data; in the writing of the manuscript, or in the decision to publish the results.

\section{References}

1. Wang, W.; Wang, C. Polyurethane for Biomedical Applications: A Review of Recent Developments; Elsevier Masson SAS: Cambridge, UK, 2012. [CrossRef]

2. Liu, Y.F.; Wu, J.L.; Zhang, J.X.; Peng, W. Feasible Evaluation of the Thermo-Mechanical Properties of Shape Memory Polyurethane for Orthodontic Archwire. J. Med. Biol. Eng. 2017, 37, 666-674. [CrossRef]

3. Huang, W. Thermo-Moisture Responsive Polyurethane Shape Memory Polymer for Biomedical Devices. Open Med. Devices J. 2010, 2, 11-19. [CrossRef]

4. Haryńska, A.; Kucinska-Lipka, J.; Sulowska, A.; Gubanska, I.; Kostrzewa, M.; Janik, H. Medical-Grade PCL Based Polyurethane System for FDM 3D Printing-Characterization and Fabrication. Materials 2019, 12, 887. [CrossRef]

5. Kuang, W.; Mather, P.T. A Latent Crosslinkable PCL-Based Polyurethane: Synthesis, Shape Memory, and Enzymatic Degradation. J. Mater. Res. 2018, 33, 2463-2476. [CrossRef]

6. Gorbunova, M.A.; Shukhardin, D.M.; Lesnichaya, V.A.; Badamshina, E.R.; Anokhin, D.V. New Polyurethane Urea Thermoplastic Elastomers with Controlled Mechanical and Thermal Properties for Medical Applications. Key Eng. Mater. 2019, 816, 187-191. [CrossRef] 
7. Gorbunova, M.; Komratova, V.; Grishchuk, A.; Badamshina, E.; Anokhin, D. The Effect of Addition of Low-Layer Graphene Nanoparticles on Structure and Mechanical Properties of Polyurethane-Based Block Copolymers. Polym. Bull. 2019, 76, 5813-5829. [CrossRef]

8. Shi, L.; Zhang, R.-Y.; Ying, W.-B.; Hu, H.; Wang, Y.-B.; Guo, Y.-Q.; Wang, W.-Q.; Tang, Z.-B.; Zhu, J. Polyether-Polyester and HMDI Based Polyurethanes: Effect of PLLA Content on Structure and Property. Chin. J. Polym. Sci. 2019, 37, 1152-1161. [CrossRef]

9. Callegari, D.; Colombi, S.; Nitti, A.; Simari, C.; Nicotera, I.; Ferrara, C.; Mustarelli, P.; Pasini, D.; Quartarone, E. Autonomous Self-Healing Strategy for Stable Sodium-Ion Battery: A Case Study of Black Phosphorus Anodes. ACS Appl. Mater. Interfaces 2021, 13, 13170-13182. [CrossRef] [PubMed]

10. Li, X.; Stribeck, A.; Schulz, I.; Pöselt, E.; Eling, B.; Hoell, A. Nanostructure of Thermally Aged Thermoplastic Polyurethane and Its Evolution under Strain. Eur. Polym. J. 2016, 81, 569-581. [CrossRef]

11. He, Y.; Xie, D.; Zhang, X. The Structure, Microphase-Separated Morphology, and Property of Polyurethanes and Polyureas. J. Mater. Sci. 2014, 49, 7339-7352. [CrossRef]

12. Yilg, E.; Yilg, I.; Yilgör, I.; Yilgör, E.; Wilkes, G.L. Critical Parameters in Designing Segmented Polyurethanes and Their Effect on Morphology and Properties: A Comprehensive Review. Polymer 2015, 58, A1-A36. [CrossRef]

13. Gorbunova, M.A.; Anokhin, D.V.; Badamshina, E.R. Recent Advances in the Synthesis and Application of Thermoplastic Semicrystalline Shape Memory Polyurethanes. Polym. Sci. Ser. B 2020, 62, 427-450. [CrossRef]

14. Yan, W.; Fang, L.; Noechel, U.; Kratz, K.; Lendlein, A. Influence of Deformation Temperature on Structural Variation and ShapeMemory Effect of a Thermoplastic Semi-Crystalline Multiblock Copolymer. Express Polym. Lett. 2015, 9, 624-635. [CrossRef]

15. Anokhin, D.V.; Gorbunova, M.A.; Estrin, Y.I.; Komratova, V.V.; Badamshina, E.R. The Role of Fast and Slow Processes in the Formation of Structure and Properties of Thermoplastic Polyurethanes. Phys. Chem. Chem. Phys. 2016, 18, 31769-31776. [CrossRef] [PubMed]

16. Li, M.; Zhang, R.; Li, X.; Wu, Q.; Chen, T.; Sun, P. High-Performance Recyclable Cross-Linked Polyurethane with Orthogonal Dynamic Bonds: The Molecular Design, Microstructures, and Macroscopic Properties. Polymer 2018, 148, 127-137. [CrossRef]

17. Zhang, H.; Zhao, H.; Zhuo, K.; Hua, Y.; Chen, J.; He, X.; Weng, W.; Xia, H. “Carbolong” Polymers With Near Infrared Triggered, Spatially Resolved and Rapid Self-Healing Properties. Polym. Chem. 2019, 10, 386-394. [CrossRef]

18. Liu, S.; Yuan, Y.; Li, J.; Sun, S.; Chen, Y. An Optomechanical Study of Mechanoluminescent Elastomeric Polyurethanes with Different Hard Segments. Polym. Chem. 2020, 11, 1877-1884. [CrossRef]

19. Hermida-Merino, D.; O’Driscoll, B.; Hart, L.R.; Harris, P.J.; Colquhoun, H.M.; Slark, A.T.; Prisacariu, C.; Hamley, I.W.; Hayes, W. Enhancement of Microphase Ordering and Mechanical Properties of Supramolecular Hydrogen-Bonded Polyurethane Networks. Polym. Chem. 2018, 9, 3406-3414. [CrossRef]

20. Koberstein, J.T.; Russell, T.P. Simultaneous SAXS-DSC Study of Multiple Endothermic Behavior in Polyether-Based Polyurethane Block Copolymers. Macromolecules 1986, 19, 714-720. [CrossRef]

21. Stribeck, A.; Dabbous, R.; Eling, B.; Pöselt, E.; Malfois, M.; Schander, E. Scattering of X-Rays during Melting and Solidification of Thermoplastic Polyurethane. Graphite as Nucleating Agent and Stabilizer of the Colloidal Melt. Polymer 2018, 153, 565-573. [CrossRef]

22. Stribeck, A.; Eling, B.; Pöselt, E.; Malfois, M.; Schander, E. Melting, Solidification, and Crystallization of a Thermoplastic Polyurethane as a Function of Hard Segment Content. Macromol. Chem. Phys. 2019, 220, 1900074. [CrossRef]

23. Tian, Q.; Yan, G.; Bai, L.; Li, X.; Zou, L.; Rosta, L.; Wacha, A.; Li, Q.; Krakovský, I.; Yan, M.; et al. Phase Mixing and Separation in Polyester Polyurethane Studied by Small-Angle Scattering: A Polydisperse Hard Sphere Model Analysis. Polymer 2018, 147, 1-7. [CrossRef]

24. Kong, Z.; Tian, Q.; Zhang, R.; Yin, J.; Shi, L.; Ying, W.B.; Hu, H.; Yao, C.; Wang, K.; Zhu, J. Reexamination of the Microphase Separation in MDI and PTMG Based Polyurethane: Fast and Continuous Association/Dissociation Processes of Hydrogen Bonding. Polymer 2019, 185, 121943. [CrossRef]

25. Sui, T.; Salvati, E.; Zhang, H.; Dolbnya, I.P.; Korsunsky, A.M. Multiscale Synchrotron Scattering Studies of the TemperatureDependent Changes in the Structure and Deformation Response of a Thermoplastic Polyurethane Elastomer. Mater. Today Adv. 2019, 4, 100024. [CrossRef]

26. Wang, Z.; Li, X.; Pöselt, E.; Eling, B.; Wang, Z. Melting Behavior of Polymorphic MDI/BD-Block TPU Investigated by Using in-Situ SAXS/WAXS and FTIR Techniques. Hydrogen Bonding Formation Causing the Inhomogeneous Melt. Polym. Test. 2021, 96, 107065. [CrossRef]

27. Stribeck, A.; Schneider, K.; Eling, B.; Poselt, E. Short-Term Morphology Relaxation of Thermoplastic Polyurethane Elastomers after Fast Strain Steps. Macromol. Mater. Eng. 2020, 2000386. [CrossRef]

28. Li, X.; Wang, H.; Xiong, B.; Pöselt, E.; Eling, B.; Men, Y. Destruction and Reorganization of Physically Cross-Linked Network of Thermoplastic Polyurethane Depending on Its Glass Transition Temperature. ACS Appl. Polym. Mater. 2019, 1, $3074-3083$. [CrossRef]

29. Stribeck, N. X-Ray Scattering of Soft Matter; Springer: Berlin/Heidelberg, Germany, 2007. [CrossRef]

30. Briber, R.M.; Thomas, E.L. Physics Investigation of Two Crystal Forms in MDI/BDO-Based Polyurethanes. J. Macromol. Sci. Part $B$ 2015, 37-41. [CrossRef]

31. Blackwell, J.; Lee, C.D. Hard-Segment Domain Sizes in MDI/Diol Polyurethane Elastomers. J. Polym. Sci. Polym. Phys. Ed. 1983, 21, 2169-2180. [CrossRef] 
32. Fu, B.X.; Hsiao, B.S.; Pagola, S.; Stephens, P.; White, H.; Rafailovich, M.; Sokolov, J.; Mather, P.T.; Jeon, H.G.; Phillips, S.; et al. Structural Development during Deformation of Polyurethane Containing Polyhedral Oligomeric Silsesquioxanes (POSS) Molecules. Polymer 2001, 42, 599-611. [CrossRef]

33. Korley, L.T.J.; Pate, B.D.; Thomas, E.L.; Hammond, P.T. Effect of the Degree of Soft and Hard Segment Ordering on the Morphology and Mechanical Behavior of Semicrystalline Segmented Polyurethanes. Polymer 2006, 47, 3073-3082. [CrossRef]

34. Bonart, R. X-Ray Investigations Concerning the Physical Structure of Cross-Linking in Segmented Urethane Elastomers. J. Macromol. Sci. Part B 1968, 2, 115-138. [CrossRef]

35. Bonart, R.; Boetzl, F.; Schmid, J. Cross Interferences in the Small-Angle X-ray Patterns of Strained Segmented PU Elastomers. J. Makromol. Chem. 1987, 188, 907-919. [CrossRef]

36. Martin, C.; Eeckhaut, G.; Mahendrasingam, A.; Blundell, D.J.; Fuller, W.; Oldman, R.J.; Bingham, S.J.; Dieing, T.; Riekel, C. Micro-SAXS and Force/Strain Measurements during the Tensile Deformation of Single Struts of an Elastomeric Polyurethane Foam. J. Synchrotron Radiat. 2000, 7, 245-250. [CrossRef] [PubMed]

37. Blundell, D.J.; Eeckhaut, G.; Fuller, W.; Mahendrasingam, A.; Martin, C. Time-Resolved SAXS/Stress-Strain Studies of Thermoplastic Polyurethanes During Mechanical Cycling at Large Strains. J. Macromol. Sci. Phys. 2004, 43, 125-142. [CrossRef]

38. Waletzko, R.S.; James Korley, L.S.T.; Pate, B.D.; Thomas, E.L.; Hammond, P.T. Role of Increased Crystallinity in DeformationInduced Structure of Segmented Thermoplastic Polyurethane Elastomers with PEO and PEO-PPO-PEO Soft Segments and HDI Hard Segments. Macromolecules 2009, 42, 2041-2053. [CrossRef]

39. Stribeck, N.; Zeinolebadi, A.; Harpen, F.; Luinstra, G.; Eling, B.; Botta, S. Thermoplastic Polyurethane Cross-Linked by Functionalized Silica. Nanostructure Evolution under Mechanical Load. Macromolecules 2013, 46, 4041-4052. [CrossRef]

40. Stribeck, A.; Li, X.; Zeinolebadi, A.; Pöselt, E.; Eling, B.; Funari, S. Morphological Changes under Strain for Different Thermoplastic Polyurethanes Monitored by SAXS Related to Strain at Break. Macromol. Chem. Phys. 2015, 216, 2318-2330. [CrossRef]

41. Lee, B.S.; Chun, B.C.; Chung, Y.; Sul, K.I.; Cho, J.W. Structure and Thermomechanical Properties of Polyurethane Block Copolymers with Shape Memory Effect. Macromolecules 2001, 34, 6431-6437. [CrossRef]

42. Pereira, I.M.; Oréfice, R.L. The Morphology and Phase Mixing Studies on Poly(Ester-Urethane) during Shape Memory Cycle. J. Mater. Sci. 2010, 45, 511-522. [CrossRef]

43. Tarasov, A.E.; Lodygina, V.P.; Komratova, V.V.; Gorbunova, M.A.; Badamshina, E.R. New IR-Spectroscopic Methods for Determining the Hydroxyl Content in Oligomers. J. Appl. Spectrosc. 2017, 84, 211-216. [CrossRef]

44. May, J.R.; Gentilini, C.; Clarke, D.E.; Odarchenko, Y.I.; Anokhin, D.V.; Ivanov, D.A.; Feldman, K.; Smith, P.; Stevens, M.M. Tailoring of Mechanical Properties of Derivatized Natural Polyamino Acids through Esterification and Tensile Deformation. RSC Adv. 2014, 4, 2096-2102. [CrossRef]

45. Odarchenko, Y.I.; Sijbrandi, N.J.; Rosenthal, M.; Kimenai, A.J.; Mes, E.P.C.; Broos, R.; Bar, G.; Dijkstra, P.J.; Feijen, J.; Ivanov, D.A. Structure formation and hydrogen bonding in all-aliphatic segmented copolymers with uniform hard segments. Acta Biomater. 2013, 9, 6143-6149. [CrossRef] [PubMed]

46. Sijbrandi, N.J.; Kimenai, A.J.; Mes, E.P.C.; Broos, R.; Bar, G.; Rosenthal, M.; Odarchenko, Y.; Ivanov, D.A.; Dijkstra, P.J.; Feijen, J. Synthesis, morphology and properties of segmented poly(ether amide)s with uniform oxalamide based hard segments. Macromolecules 2012, 45, 3948-3961. [CrossRef]

47. Yeh, F.; Hsiao, B.S.; Sauer, B.B.; Michel, S.; Siesler, H.W. In-Situ Studies of Structure Development during Deformation of a Segmented Poly(Urethane-urea) Elastomer. Macromolecules 2003, 36, 1940-1954. [CrossRef]

48. Zhu, L.; Mimnaugh, B.R.; Ge, Q.; Quirk, R.P.; Cheng, S.Z.D.; Thomas, E.L.; Lotz, B.; Hsiao, B.S.; Yeh, F.; Liu, L. Hard and Soft Confinement Effects on Polymer Crystallization in Microphase Separated Cylinder-Forming PEO-b-PS/PS Blends. Polymer 2001, 42, 9121-9131. [CrossRef]

49. Zhou, Y.; Ahn, S.K.; Lakhman, R.K.; Gopinadhan, M.; Osuji, C.O.; Kasi, R.M. Tailoring Crystallization Behavior of PEO-Based Liquid Crystalline Block Copolymers through Variation in Liquid Crystalline Content. Macromolecules 2011, 44, 3924-3934. [CrossRef] 